\title{
Creativity Methods Adoption in Higher Education: Perspectives of Educators and Students
}

\author{
Zhengya Gong a*, Sohail Ahmed Soomro ${ }^{a, b}$, Vijayakumar Nanjappana, Georgi V. Georgieva \\ ${ }^{a}$ Center for Ubiquitous Computing, University of Oulu, Finland \\ ${ }^{b}$ Electrical Engineering Department, Sukkur IBA University, Pakistan \\ *Corresponding author e-mail: Zhengya.Gong@oulu.fi
}

\begin{abstract}
:
Numerous higher education institutions offer courses aimed at enhancing learners' creativity, especially in design studies. However, the differences in the adoption of creativity methods in teaching from educators' and students' perspectives are still underexplored. In this study, we used a custom-designed online survey questionnaire to understand educator and student perceptions of creativity methods in creativityrelated courses in higher education. Our study results indicate apparent differences between students and instructors regarding their motivations for participating in creativity-related courses, preferences for the most effective creativity methods, and evaluations of creativity methods. We believe that our study results suggest helpful directions for the teaching of creativity methods in higher education.
\end{abstract}

Keywords: creativity methods, creativity education, design education, teaching methods

\section{Introduction}

With accelerated globalization, companies and organizations encounter more complex situations. They require more efficient human resources, including enhancing their leaders' and employees' creativity to manage upcoming or unpredictable events, and create innovative products (Sutapa et al., 2017; Tang et al., 2018). Creativity enables individuals to use opportunities and better respond to challenges in their career and personal life (Fraser \& Greenhalgh, 2001; Lee \& Kim, 2019). Creativity also helps students be better prepared to enter the job market and provides them with more innovative ideas and solutions to deal with different types of unexpected challenges and advance their careers (Sternberg, 1999). Therefore, higher education institutions have recognised the importance of creativity and have adopted creativity methods in courses to foster students' creativity and produce creative work (Kolko, 2015; Masson et al., 2013; Wolff \& Martins, 2015). However, it is necessary to explore the effective creativity methods from educators' and students' perspectives 
further. Therefore, we designed and administered a questionnaire to investigate the creativityrelated courses and adopted creativity methods from educators' and students' perspectives in higher education teaching.

\section{Related Work}

\subsection{Creativity methods}

Creativity methods are employed to encourage creative actions and enhance creativity by including techniques for generating ideas. Numerous studies applied creativity methods to encourage students to generate novel and useful ideas, increase learning outcomes, and enhance creativity in higher education (Al-Samarraie \& Hurmuzan, 2018; Jahnke et al., 2017; Jahnke \& Liebscher, 2020; Matraeva et al., 2020). One of the most popular and widely applied creativity methods is brainstorming. For example, Al-Samarraie and Hurmuzan reviewed 1677 papers based on the adoption of brainstorming in higher education and proposed the challenges and solutions (Al-Samarraie \& Hurmuzan, 2018). Moreover, Sosa recognized the research gaps between brainstorming and specific area-design creativity and encouraged researchers to focus more on design creativity, facilitation, association, revealing assumptions, methodology, design ideas, design briefs, and ideation purposes (Sosa, 2020). Furthermore, Nutzmann et al. surveyed creativity methods, and the results indicated that students and educators were willing to apply the different creativity methods (Nutzmann et al., 2019).

With the use of pioneering innovative technologies, numerous researchers explored alternative methods (e.g., additive manufacturing, or virtual reality) that support students to design and materialize creative ideas (Barhoush et al., 2020; Campbell \& Bernabei, 2017; Ford \& Minshall, 2019; Georgiev et al., 2017; Maiden, 2019; Marinussen \& de Rooij, 2019; Men \& Bryan-Kinns, 2019; Watschke et al., 2017; Williford, 2017). For example, Georgiev et al. explored how to capture creativity in a specific workplace. They proposed a framework that included three methods-creative fabrication spaces, interactions in the making, and in-depth cognition and thinking-to capture and understand creativity in digital fabrication laboratories (Georgiev et al., 2017). Researchers also combined the new technologies and creativity methods to inspire students to generate more creative outcomes, such as using virtual reality in brainstorming (Gong et al., 2021; Gong \& Georgiev, 2020; Guegan et al., 2016; Hu et al., 2016).

\subsection{The different views on creativity of educators and students}

Although most adopted teaching methods contribute to students' understanding of the course content and increase the learning outcome, students and educators hold different views (Albaradie, 2018; De Alencar \& Fleith, 2004; Kazerounian \& Foley, 2007; Nutzmann et al., 2019). For example, a study indicated that educators argued that the problem-solving method is time-consuming. In contrast, students had a positive attitude towards the problem-solving method, perceived it as an intellectual challenge, and wanted to attempt it (Albaradie, 2018). Furthermore, regarding the factors that foster creativity in teaching, there were significant differences between educators' and students' perspectives, such as their evaluation of the teaching methodology. The educators had a more positive attitude towards all the factors than students (De Alencar \& Fleith, 2004). Another study also showed that although educators argued they valued creativity and provided students with creativity techniques when teaching, the students disagreed with this view. More precisely, students did not believe that the educators valued creativity or provided any techniques to improve their creativity (Kazerounian \& Foley, 2007). 
Moreover, many educators believe that the creativity methods they adopted in teaching help students be creative (Jahnke et al., 2017; Jones et al., 2014); however, students sometimes disagree with this stance. For example, Rodgers and Jones surveyed and collected the results from architecture and product design students and tutors by asking ten questions. Almost all design tutors believed that they enhanced the students' creativity. In contrast, approximately $40 \%$ of design students did not think that the tutors helped them to be more creative. Moreover, when surveying participants' views on whether the teaching methods promoted students' creativity, approximately $90 \%$ of tutors thought the creativity methods used in their teaching positively affected students' creativity. However, approximately half of the students were unsure of this (Rodgers \& Jones, 2017).

Another study conducted a survey with teachers and students at university and reported students' evaluation of the educators' creativity behaviours. According to students, educators do not encourage them sufficiently to be involved during the classes, which is different from the educators' perspective (Gaspar \& Mabic, 2015). Moreover, Fleith interviewed educators and students to explore the role of creativity in higher education. Although both groups realized the importance of creativity and noted the barriers in promoting creative thinking, each group argued that others, rather than themselves, lacked incentives to be creative (Fleith, 2019).

\section{Methods}

Many researchers continue to explore the creativity methods used in higher education to enhance students' creativity (Marlina et al., 2020; Nutzmann et al., 2019; Puspita, 2020). Creativity-related courses involve creativity methods and target students' creativity, such as application within the design thinking, data visualization, and user-centered product concept design courses. During those courses, the educators applied various creativity methods to inspire students' diverse thinking, and to generate creative outputs. However, only a few studies have focused on the application of creativity methods considering the different views of educators and students (Albaradie, 2018; De Alencar \& Fleith, 2004; Kazerounian \& Foley, 2007; Nutzmann et al., 2019). It is necessary to analyse the differences between educators' and students' perspectives. To deepen our understanding, we conducted a study based on a questionnaire to answer the following research questions (RQs):

- What is the participation and adoption of creativity-related courses (RQ 1)?

- What are the differences in the perspectives of educators and students regarding the following issues?

- Motivation for participating in the creativity-related course (RQ 2)

- Effectiveness of creativity methods (RQ 3)

- Evaluations of creativity methods (RQ 4)

\subsection{The survey questionnaire content}

The questionnaire aimed to investigate adopted creativity methods in higher education teaching, by asking questions about participants' teaching or learning courses related to creativity or creativity methods. A seven-page questionnaire was developed and divided into three sections to ask questions related to the participants' personal information, the creativity-related course content, and the creativity methods used in the courses, as shown in Figure 1. 
Background investigation asked questions about participants' demographic background, such as gender and age. Creativity-related course investigation posed queries about the creativity-related course. If the students participated in the related course, they answered questions about the name of the course, and so on, as shown in Figure 1. However, if the students did not participate in the related course, they advanced to the end of the questionnaire to answer questions related to creativity. The creativity methods investigation section explored the creativity methods used in the related course. In the last section, the participants were asked to answer questions about their feelings and behaviours during or after using the creativity methods, using a 5-point Likert scale.

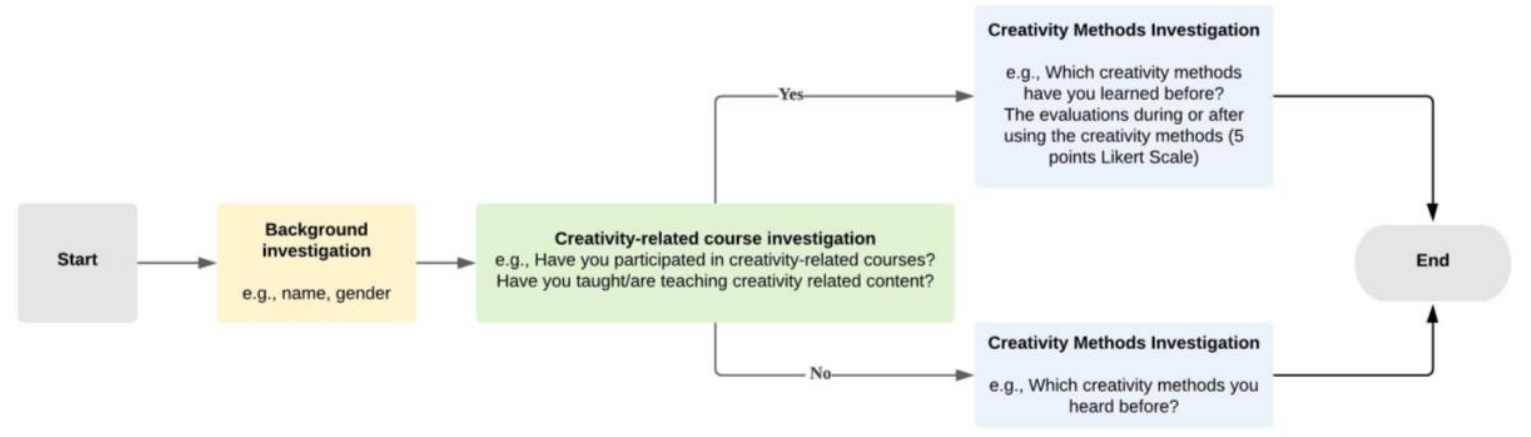

Figure 1: The contents and the sequence of the questionnaire.

\subsection{Respondents recruitment}

We used social media platforms (e.g., WeChat and Facebook) and sent emails (e.g., PhD Design mailing list at jiscmail.ac.uk) to recruit respondents. The respondents completed the questionnaire using Microsoft Forms. Participation in in the survey was voluntary. They were informed that their responses would remain confidential, and that the anonymised data may be used in publications, reports, web pages, and other research outputs.

\subsection{Respondents' background}

From 12 to 28 January 2021, 119 individuals from different countries (including China, Finland, France, Sweden, United Kingdom, United States of America, and others) participated in our questionnaire study. We excluded 37 responses (e.g., respondents with high school diploma, other levels of education, company employees, and self-employed/freelancers), because we aimed to investigate the creativity methods in higher education. Moreover, we excluded the responses $(n=$ 4) because of too short response time, less than $90 \mathrm{~s}$ (without participation in creativity-related course), or less than $350 \mathrm{~s}$ (participation in the creativity-related course), assuming that short response times indicated the low data quality (Greszki et al., 2015). After applying the criteria mentioned above, only 78 responses were considered for our analysis. Our respondents included 46 females, 27 males, and 5 did not specify their gender (mean age of the respondents $=31.5$, SD $=$ 12.78).

\section{Results and Discussion}

\subsection{Creativity-related course}

In total, 32 participants participated in the creativity-related course, accounting for $41 \%$ of all participants attend a university that offers a creativity-related course. Moreover, almost half of the 
participants participated in more than one creativity-related course. In addition, the percentage per university year was different: 16.7\% (1st), 28.3\% (2nd), 23.3\% (3rd), and 31.7\% (4th), respectively, which means that $85 \%$ of universities offered creativity-related courses in the second year. Furthermore, around half of the creativity-related courses have less than 30 enrolled students, and almost $10 \%$ of the creativity-related courses have more than 50 enrolled students.

Regarding the assessment types of the courses participated in, projects were the most popular assessment type and accounted for $28.3 \%$ of total assessments. Other assessment types, in order of popularity, were presentations $(20 \%)$, written reports $(15 \%)$, analysis of case studies $(10 \%)$, not assessed and written exams (8.3\%), oral exams (3.3\%), and lab reports and other assessments $(1.7 \%)$. Accordingly, we answered RQ 1.

\subsection{Motivations for participation in a creativity-related course}

A 5-point Likert scale was used to evaluate how importance different motivations are for participating in creativity-related courses. The results showed that $78.2 \%$ of responses assigned 'very important' or 'extremely important' for each reason, and $4.1 \%$ of responses were 'not important at all' or 'slightly important' to four questions (availability of appropriate content, to gain an interest in learning, to understand the related course, and sustainability considerations for learning). The most important motivation of participating in creativity-related courses was to enhances thinking capability.

Table 1: Test statistics of motivations of educators and students

\begin{tabular}{|c|c|c|c|c|c|c|c|c|c|c|}
\hline & 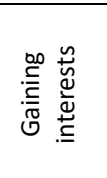 & 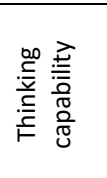 & 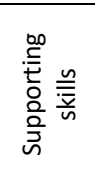 & 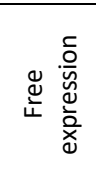 & 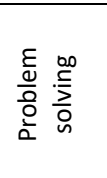 & 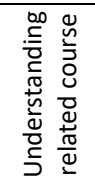 & 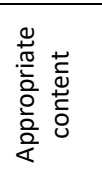 & 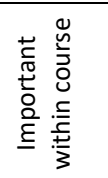 & 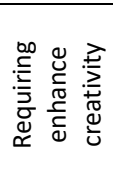 & 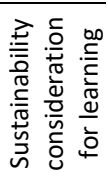 \\
\hline Mann & 103.000 & 102.500 & 85.500 & 61.500 & 107.000 & 86.500 & 100.500 & 110.000 & 90.000 & 48.000 \\
\hline Asymp. Sig. (2-tailed) & .590 & .557 & 201 & .022 & .708 & .213 & .533 & .816 & .260 & .004 \\
\hline
\end{tabular}

Comparison of differences in motivations for participating in creativity-related courses between educators and students revealed that students had a more positive attitude because $50.9 \%$ of them believed that participating in the course was extremely important, compared to $28.6 \%$ of educators. In addition, a Mann-Whitney $U$ test was conducted to confirm the difference in motivations. The results showed that the scores for how creativity enables individual's freedom of expression were statistically significantly different for educators (mean rank $=13.93$ ) and students (mean rank = 21.41) $U=61.5, z=-2.284, p=0.022$. Scores for how creativity is important for sustainability considerations were statistically significantly different for educators (mean rank $=13.29$ ) and students (mean rank $=22.64$ ) $, U=48, z=-2.879, p=0.004$. This was assessed using an exact sampling distribution for $U$ (Dinneen \& Blakesley, 1973), as shown in Table 1; therefore, RQ2 was answered.

We also examined other motivations that are not included above. The responses of educators included: 1) creative thinking allows us to see a situation from a different perspective, which could increase synergy in a collaborative group situation; 2 ) critical innovative thinking should be used to address real-life issues through creativity; and 3) creativity requires flexible thinking in every sense. In addition, the students' answers included: 1) I can make myself feel comfortable by participating in the course; 2) creativity is something that many people do not have, so being more creative is a good way to stand out in interviews; 3 ) creativity is an essential element to avoid a boring life; therefore, it is indispensable; and 4) creativity is essential for personal development. These responses implied that individuals realised that creativity is important for different areas of their daily lives, including 
work, studies, research, and emotional needs, and that their creativity must be practised and developed.

\subsection{The most effective creativity methods}

We selected 19 creativity methods that are commonly used in higher education teaching (Leopoldino et al., 2016). The results indicated that the most popular creativity methods were mind mapping (12.98\%), brainstorming (9.61\%), thinking outside the box (8.65\%), and storyboards $(7.69 \%)$ in higher education. However, C-sketch, practical theory of inventive problem solving (PRIZ), the theory of inventive problem solving (TRIZ), $6-3-5$, and brain shifter only accounted for $0.48 \%, 0.96 \%, 1.92 \%$, $1.44 \%$, and 1.92 of creativity methods, respectively.

We also compared the most effective creativity methods from the educators' and students' perspectives (Figure 2). The results showed that both educators and students considered that mind mapping the most effective method, followed by brainstorming. Furthermore, 6-3-5 and 3D printing were effective from the educators' perspective but not from that of the students. In contrast, braindrawing and think outside the box are as effective as brainstorming from the students' perspective, whereas the educators thought it was less effective than brainstorming. Moreover, few students thought that six thinking hats as an effective method, but the educators held a different view; therefore, RQ 3 was answered, as shown in Figure 2.

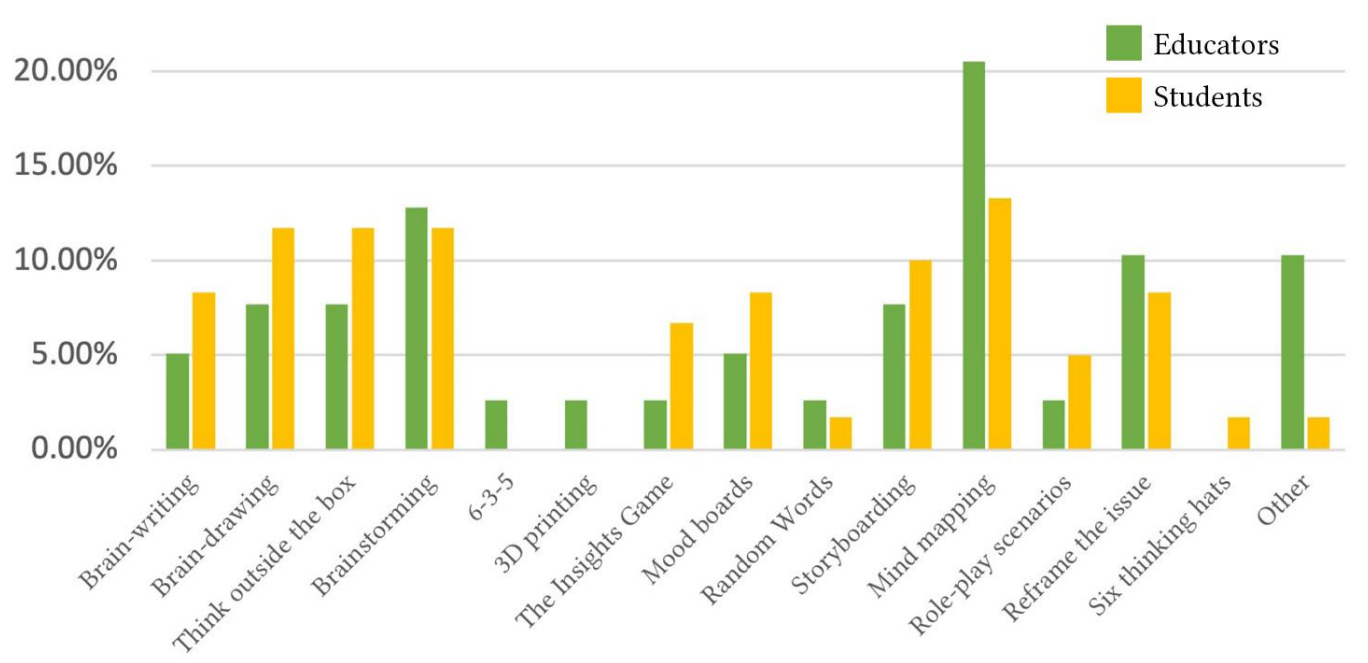

Figure 2. The bar chart of the most effective creativity methods between educators and students

\subsection{The evaluations of the most effective creativity methods}

All participants had a positive attitude towards effective creativity methods of learning or teaching, with a mean rank ranging from 3.09 to 4.28 . We compared the answers of educators and students, and identified three differences, which are shown in Table 4. Accordingly, we answered RQ 4 and the findings are summarised as follows: 1 ) the levels of familiarity of educators (mean rank $=19.52$ ) were statistically significantly higher than those of students (mean rank $=10.73$ ), $U=52, z=-2.709, p=$ $.011 ; 2$ ) the levels of enthusiasm of educators (mean rank $=18.64$ ) were statistically significantly higher than those of students (mean rank $=12.41$ ), $U=70.5, z=-2.153, p=.031$; and 3 ) the levels of motivation or commitment of educators (mean rank $=18.67$ ) were statistically significantly higher than those of students (mean rank $=12.36$ ), $U=70, z=-2.008, p=.045$. 


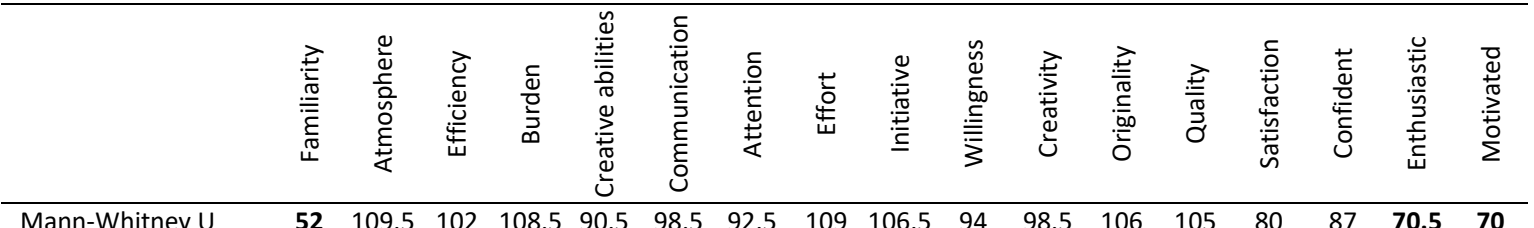

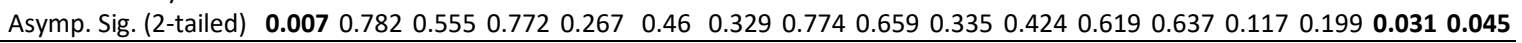

However, a particular observation emerged. Although the students expressed a more positive attitude than educators towards participation in the creativity-related courses, they felt less motivation or commitment, and enthusiasm than educators after taking part in the creativity-related courses. This can be attributed to the partial disappointment of students in learning the creativity methods, which educators did not recognise. This indicated that it is necessary to explore further the reasons for decreased motivation and enthusiasm after applying creativity methods and improve the teaching process.

\section{Conclusion}

This study showed that the perceptions of adopted creativity-related courses and creativity methods differ from educators' and students' perspectives. The respondents reported positive attitudes toward attending creativity-related courses and practising creativity methods for their study, work, and research. This study's main findings are summarised as follows: 1$)$ students had greater motivations for participating in creativity-related courses compared to educators, especially in the categories of freedom of expression and its importance for sustainability considerations; 2 ) the most popular creativity methods are mind mapping, brainstorming, thinking outside the box, and storyboards; 3 ) educators' and students' perspectives differ on the most effective creativity methods ; 4) educators and students evaluated differently the sub-categories of the most effective adopted creativity methods, and students felt less motivated and enthusiastic after participating in the creativity-related course, which should be explored further.

This study also revealed that approximately half of the creativity-related courses have less than 30 enrolled students, and most universities offered the course after the first year. An online course was the most popular teaching mode, while practice workshops were the least popular. The participants reported that because of the coronavirus disease of 2019 , the university had changed almost all courses to facilitate remote lectures. Regarding course assessments, projects, posters, and presentations were the preferred assessment types for all participants.

Concerning the limitations, first, our study may have been prone to selection bias, because it might have attracted people specifically interested in creativity and creativity methods, such as design educators and students. Second, there were few responses, and the sample was small; therefore, it would be better to collect a larger number of responses in the future. The third limitation is that we did not inquire about the actual content of the exercise, which means that the process or frequency of applying the creative methods might have been different.

Overall, the survey results indicated that although creativity is essential for all individuals, creativity training or teaching in higher education is insufficient. Therefore, we suggest that universities provide more and customised creativity-related courses, while educators should deepen their inhibiting students' creativity, and devise approaches to empower it. This can be done for example, by applying various creativity methods during classes and by using effective and specific creativity methods to aid students' work. 


\section{References}

Albaradie, R. (2018). Perception of students and teachers about didactic teaching: A cross-sectional study. Saudi Journal for Health Sciences, 7(2), 107. https://doi.org/10.4103/sjhs.sjhs_28_18

Al-Samarraie, H., \& Hurmuzan, S. (2018). A review of brainstorming techniques in higher education. Thinking Skills and Creativity, 27, 78-91. https://doi.org/10.1016/j.tsc.2017.12.002

Barhoush, Y., Georgiev, G. V., \& Loudon, B. (2020). Empathy and Idea Generation: Exploring the Design of a Virtual Reality Controller for Rehabilitation Purposes. Proceedings of the Sixth International Conference on Design Creativity (ICDC 2020), 287-294. https://doi.org/10.35199/ICDC.2020.36

Campbell, R. I., \& Bernabei, R. (2017). Increasing product attachment through personalised design of additively manufactured products. Proceedings of the 21st International Conference on Engineering Design (ICED 17), Vol 5: Design for X, Design to X, 071-079.

De Alencar E. M. L. S., \& Fleith D. D. S. (2004). Creativity in University Courses: Perceptions of Professors and Students. Gifted and Talented International, 19(1), 24-28. https://doi.org/10.1080/15332276.2004.11673029

Dinneen, L. C., \& Blakesley, B. C. (1973). Algorithm AS 62: A Generator for the Sampling Distribution of the Mann- Whitney U Statistic. Journal of the Royal Statistical Society. Series C (Applied Statistics), 22(2), 269-273. https://doi.org/10.2307/2346934

Fleith, D. de S. (2019). The role of creativity in graduate education according to students and professors. Estudos de Psicologia (Campinas), 36. https://doi.org/10.1590/1982$0275201936 \mathrm{e} 180045$

Ford, S., \& Minshall, T. (2019). Invited review article: Where and how 3D printing is used in teaching and education. Additive Manufacturing, 25, 131-150. https://doi.org/10.1016/j.addma.2018.10.028

Fraser, S. W., \& Greenhalgh, T. (2001). Coping with complexity: Educating for capability. BMJ, 323(7316), 799-803. https://doi.org/10.1136/bmj.323.7316.799

Gaspar, D., \& Mabic, M. (2015). Creativity in Higher Education. Universal Journal of Educational Research, 3(9), 598-605. https://doi.org/10.13189/ujer.2015.030903

Georgiev, G. V., Sánchez Milara, I., \& Ferreira, D. (2017). A Framework for Capturing Creativity in Digital Fabrication. The Design Journal, 20(sup1), S3659-S3668. https://doi.org/10.1080/14606925.2017.1352870

Gong, Z., \& Georgiev, G. V. (2020). Literature Review: Existing Methods Using VR to Enhance Creativity. Proceedings of the Sixth International Conference on Design Creativity, 117-124. https://doi.org/10.35199/ICDC.2020.15

Gong, Z., Nanjappan, V., Soomro, S. A., \& Georgiev, G. V. (2021). Virtual Brainstorming and Creativity: An Analysis of Measures, Avatars, Environments, Interfaces, and applications. Proceedings of the Design Society, 1, 3399-3408. https://doi.org/10.1017/pds.2021.601

Greszki, R., Meyer, M., \& Schoen, H. (2015). Exploring the Effects of Removing "Too Fast" Responses and Respondents from Web Surveys. Public Opinion Quarterly, 79(2), 471-503. https://doi.org/10.1093/poq/nfu058

Guegan, J., Buisine, S., Mantelet, F., Maranzana, N., \& Segonds, F. (2016). Avatar-mediated creativity: When embodying inventors makes engineers more creative. Computers in Human Behavior, 61, 165-175. https://doi.org/10.1016/j.chb.2016.03.024

Hu, R., Wu, Y.-Y., \& Shieh, C.-J. (2016). Effects of Virtual Reality Integrated Creative Thinking Instruction on Students' Creative Thinking Abilities. Eurasia Journal of Mathematics Science and Technology Education, 12(3), 477-486. 
Jahnke, I., Haertel, T., \& Wildt, J. (2017). Teachers' conceptions of student creativity in higher education. Innovations in Education and Teaching International, 54(1), 87-95. https://doi.org/10.1080/14703297.2015.1088396

Jahnke, I., \& Liebscher, J. (2020). Three types of integrated course designs for using mobile technologies to support creativity in higher education. Computers \& Education, 146, 103782. https://doi.org/10.1016/j.compedu.2019.103782

Jones, P., Rodgers, P. A., \& Nicholl, B. (2014). A study of university design tutors' perceptions of creativity. International Journal of Design Creativity and Innovation, 2(2), 97-108. https://doi.org/10.1080/21650349.2013.819170

Kazerounian, K., \& Foley, S. (2007). Barriers to Creativity in Engineering Education: A Study of Instructors and Students Perceptions. Journal of Mechanical Design, 129(7), 761-768. https://doi.org/10.1115/1.2739569

Kolko, J. (2015). New Techniques in Industrial Design Education. In The 6th International Conference of the European Academy of Design Proceedings, Design System Evolution, 29-30.

Lee, W.-S., \& Kim, B.-Y. (2019). The Effects of Career Orientations on Entrepreneurial Satisfaction and Business Sustainability. The Journal of Asian Finance, Economics, and Business, 6(4), 235-248. https://doi.org/10.13106/jafeb.2019.vol6.no4.235

Leopoldino, K. D. M., González, M. O. A., Ferreira, P. de O., Pereira, J. R., \& Souto, M. E. C. (2016). Creativity techniques: A systematic literature review. 14, 6.

Maiden, N. (2019). Digital Creativity Support: Designing Al to augment human creativity. 145-146. https://doi.org/10.5771/9783956505508-145

Marinussen, M., \& de Rooij, A. (2019). Being Yourself to be Creative: How Self-Similar Avatars can Support the Generation of Original Ideas in Virtual Environments. Proceedings of the 2019 on Creativity and Cognition, 285-293. https://doi.org/10.1145/3325480.3325482

Marlina, W. A., Rahmi, D. Y., \& Antoni, R. (2020). Enhancing Student's Understanding in Feasible Study Subject by Using Blended Learning Methods (Mind Mapping, Project Based Learning and Coursera). In The 3rd International Conference on Educational Development and Quality Assurance (ICED-QA 2020), 24-31.

Masson, P. L., Hatchuel, A., \& Weil, B. (2013). Teaching at Bauhaus: Improving design capacities of creative people? From modular to generic creativity in design-driven innovation. In 10th European Academy of Design Conference: Crafting the Future. University of Gothenburg., 23-.

Matraeva, A. D., Rybakova, M. V., Vinichenko, M. V., Oseev, A. A., \& Ljapunova, N. V. (2020). Development of Creativity of Students in Higher Educational Institutions: Assessment of Students and Experts. Universal Journal of Educational Research, 8(1), 8-16. https://doi.org/10.13189/ujer.2020.080102

Men, L., \& Bryan-Kinns, N. (2019). LeMo: Exploring Virtual Space for Collaborative Creativity. Proceedings of the 2019 on Creativity and Cognition, 71-82. https://doi.org/10.1145/3325480.3325495

Nutzmann, M., Sauer, T., VOß, M., \& Bozkurt, H. (2019). Survey on Learning Concepts Applying Creativity Methods in Education and Industry. Proceedings of the 21st International Conference on Engineering and Product Design Education (E\&PDE 2019), University of Strathclyde, Glasgow., 6.

Puspita, Y. (2020). Application of Blended Learning (Discovery Learning, Small Group Discussion, Case Study, Role Play \& Simulation, Cooperative Learning, and Collaborative Learning) to Improve Learning Activities and Achivements in Lobby and Negotiation Course. In The 3rd International Conference on Educational Development and Quality Assurance (ICED-QA 2020) Atlantis Press., 441-446.

Rodgers, P. A., \& Jones, P. (2017). Comparing University Design Students' and Tutors' Perceptions of Creativity. The Design Journal, 20(4), 435-457. https://doi.org/10.1080/14606925.2017.1323503 
Sosa, R. (2020). Retrospective and Prospective of the Study of Design Creativity: 80 Years into the Past and the Future. Proceedings of the Sixth International Conference on Design Creativity (ICDC 2020), 001-010. https://doi.org/10.35199/ICDC.2020.01

Sternberg, R. J. (1999). Handbook of Creativity. Cambridge University Press.

Sutapa, S., Mulyana, M., \& Wasitowati, W. (2017). The Role of Market Orientation, Creativity and Innovation in Creating Competitive Advantages and Creative Industry Performance. JDM (Jurnal Dinamika Manajemen), 8(2), 152-166. https://doi.org/10.15294/jdm.v1i1.12756

Tang, C., Byrge, C., \& Zhou, J. (2018). Creativity Perspective on Entrepreneurship. The Palgrave Handbook of Multidisciplinary Perspectives on Entrepreneurship, 81-102. https://doi.org/10.1007/978-3-319-91611-8_5

Watschke, H., Bavendiek, A.-K., Giannakos, A., \& Vietor, T. (2017). A methodical approach to support ideation for additive manufacturing in design education. 041-050.

Williford, B. (2017). SketchTivity: Improving Creativity by Learning Sketching with an Intelligent Tutoring System. Proceedings of the 2017 ACM SIGCHI Conference on Creativity and Cognition, 477-483. https://doi.org/10.1145/3059454.3078695

Wolff, F., \& Martins, V. S. (2015). Competences in Design Education. The Value of Design Research: 11th European Academy of Design. https://doi.org/10.13140/RG.2.1.2555.3764

Author Bios:

Zhengya Gong is a Ph.D. researcher at the Center for Ubiquitous Computing, University of Oulu, Finland. Her work focuses on design creativity, creative methods, design cognition, design thinking, and the effects of cultural bias in applying creativity methods.

Sohail Ahmed Soomro is a Ph.D. researcher at the Center for Ubiquitous Computing, University of Oulu, Finland. His research interests are in digital fabrication, engineering design and user interactions.

Vijayakumar Nanjappan is a Postdoctoral Researcher at the Center for Ubiquitous Computing, University of Oulu, Finland. His research interests include human-computer interaction, wearable devices, smart textiles, digital fabrication and learning technologies.

Georgi V. Georgiev is an Associate Professor at the Center for Ubiquitous Computing, University of Oulu, Finland. His research interests are design creativity, idea generation, design cognition, digital fabrication and prototyping, design thinking, user interaction, and user experience.

Acknowledgements: This study has been partially financially supported by Academy of Finland 6Genesis Flagship (grant 318927), by EDUFI Fellowship (grant TM-20-11342), and by China Scholarship Council (NO: 202107960006). We also wish to thank Professor Lei Zhang, Jiyao Yu, Jiang Liu and all the participants for their help. 